\title{
Floristic Variation of Tree Communities In Island Forests of Pulau Tuba and Gunung Raya Forest Reserve, Langkawi
}

\author{
F Pardi ${ }^{1 *}$, M N Mohd Said ${ }^{2}$, A Ismail ${ }^{1}$, N J Sidik ${ }^{1}, K_{\text {A Radzun }}{ }^{1}$, N S Ishak ${ }^{3}$ \\ ${ }^{1}$ School of Biology, Faculty of Applied Sciences, Universiti Teknologi MARA, 40450 Shah Alam, Selangor, Malaysia \\ ${ }^{2}$ School of Environmental and Natural Resource Sciences, Faculty of Science and Technology, Universiti Kebangsaan Malaysia, 43600, \\ UKM Bangi, Selangor \\ ${ }^{3}$ Pusat Asasi, Universiti Teknologi MARA Cawangan Selangor, Kampus Dengkil, 43800 Dengkil, Selangor \\ *Corresponding author E-mail: faezahpardi@salam.uitm.edu.my
}

\begin{abstract}
Island forests are among forest habitats that are vulnerable to natural and anthropogenic disturbances, whereby the disturbances would influence the survival of biological species of the ecosystems. Langkawi Archipelago contains many small island forests and rapid development of tourism industry within this archipelago might contribute impacts to the tree flora of the forest communities on the small islands. Hence, in this study the species richness and floristic variation pattern of tree communities of two selected island forests in the Langkawi Archipelago were explored, and data gathered are anticipated to be used for management of island forests in Langkawi. Tree survey was carried out in 10 study plots of $20 \mathrm{~m}$ x $25 \mathrm{~m}$ each, at island forests of Pulau Tuba Forest Reserve (PTB) and Gunung Raya Forest Reserve (GRFR), making the total of 20 study plots. All trees with diameter at breast height (dbh) of $5.0 \mathrm{~cm}$ and above were enumerated and tree species were identified. Species data were analyzed for diversity and richness using the Shannon and Margalef indices; whilst Detrended Correspondence Analysis (DCA) was used to determine floristic pattern. A total of 1062 trees were recorded from all study plots which comprised of 49 families, 134 genera and 213 tree species. The GRFR exhibited the highest species number of 135 tree species, followed by the PTB (106 tree species). Species accumulation curves showed that the curves were far from reaching the asymptote even when the whole dataset were combined. The DCA ordination diagram clearly grouped the study plots by their geological formation that indicated a gradient of species change in GRFR and PTB sites.
\end{abstract}

Keywords: Detrended Correspondence Analysis ; ecology ; Langkawi Island; rarefaction ; tree diversity

\section{Introduction}

Island ecosystem has always become the interest of ecologist [1] due to the vulnerability of the ecosystems to biological invasions. Forest ecosystems of small islands are more sensitive compared to those forest ecosystems of large islands whereby on the small islands, the forest vegetation display special growth conditions such as slow-growth trees, having small tree diameter and small leaves for its adaptation to the extreme weather condition. Plant populations on islands and mainland often differ in their distribution because of physical environment factors. Currently, majority of the island biota are severely threatened due to anthropogenic pressures [5]. There has been little attention to the conservation effort on forested island as there are many challenges of these biological island communities. Firstly, island system have remarkable high endemism of biological communities due to low species immigration, thus making them as a hotspots of biodiversity [6]. Furthermore, island species are prone to be affected by negative impacts of novel pathogen, competition of new species, predation and herbivory [7].

This study aimed to determine the variation of tree species richness between two forest habitats within Langkawi Archipelago that include of Pulau Tuba (PTB) and Gunung Raya Forest Reserve (GRFR) Langkawi, thus reveal differences in species composition between those islands. This study is anticipated to contribute knowledge on patterns of tree species composition in island forests of Langkawi archipelago, which is essential for sustainable management of the forest ecosystems.

\section{Materials and method}

\subsection{Study Area}

The Langkawi Archipelago lies west of Peninsular Malaysia in the Andaman Sea near the Malaysian-Thai border. The archipelago consists of 99 islands at high tide and 104 islands at low tide [8]. Sampling was conducted at two island forests in Langkawi Archipelago, which include Gunung Raya Forest Reserve (GRFR) and Pulau Tuba (PTB) (Figure 1). Ten study plots of $25 \mathrm{~m} \times 20 \mathrm{~m}$ each were established randomly at each study area, making the total of 20 study plots (total area of 1 hectare). The detailed GPS coordinates and elevation for all 20 plots in the study area are shown in Table 1.

Table 1: Coordinates and elevation for 20 plots at the Pulau Tuba and Gunung Raya Forest Reserve, Langkawi Archipelago.

\begin{tabular}{|c|c|c|}
\hline Plot & Coordinate & Elevation (m) \\
\hline GRFR1 & $\mathrm{N} 06^{0} 22.115^{\prime}$ E $099^{0} 47.859^{\prime}$ & 122 \\
\hline GRFR2 & N $06^{0} 22.216^{\prime}$ E $099^{0} 47.958^{\prime}$ & 152 \\
\hline GRFR3 & N $06^{0} 22.226^{\prime}$ E $099^{\circ} 48.094^{\prime}$ & 167 \\
\hline GRFR4 & N $06^{0} 21.404^{\prime}$ E $099^{\circ} 48.195^{\prime}$ & 138 \\
\hline GRFR5 & N $06^{0} 21.333^{\prime}$ E $099^{0} 48.297^{\prime}$ & 230 \\
\hline GRFR6 & $\mathrm{N} 06^{0} 22.122^{\prime}$ E $099^{\circ} 48.873$, & 713 \\
\hline
\end{tabular}




\begin{tabular}{clc} 
GRFR7 & N $06^{0} 22.122^{\prime}$ E $099^{0} 48.759^{\prime}$ & 567 \\
GRFR8 & N $06^{0} 22.089^{\prime}$ E $099^{0} 48.625^{\prime}$ & 635 \\
GRFR9 & N $06^{0} 22.032^{\prime}$ E $099^{0} 48.469^{\prime}$ & 527 \\
GRFR10 & N $06^{0} 21.925^{\prime}$ E $099^{0} 48.313^{\prime}$ & 402 \\
PTB1 & N $06^{0} 15.324^{\prime}$ E $099^{0} 50.297^{\prime}$ & 69 \\
PTB2 & N $06^{0} 15.340^{\prime}$ E $099^{0} 50.327^{\prime}$ & 91 \\
PTB3 & N $06^{0} 15.347^{\prime}$ E $099^{0} 50.383^{\prime}$ & 102 \\
PTB4 & N $06^{0} 15.342^{\prime}$ E $099^{0} 50.365^{\prime}$ & 95 \\
PTB5 & N $06^{0} 15.324^{\prime}$ E $099^{0} 50.396^{\prime}$ & 138 \\
PTB6 & N $06^{0} 15.340^{\prime}$ E $099^{0} 50.412^{\prime}$ & 115 \\
PTB7 & N $06^{0} 15.307^{\prime}$ E $099^{0} 50.452^{\prime}$ & 125 \\
PTB8 & N $06^{0} 15.299^{\prime}$ E $099^{0} 50.476^{\prime}$ & 116 \\
PTB9 & N $06^{0} 15.259^{\prime}$ E $099^{0} 50.509^{\prime}$ & 171 \\
PTB10 & N $06^{0} 15.243^{\prime}$ E $099^{0} 50.482^{\prime}$ & 164 \\
\hline
\end{tabular}

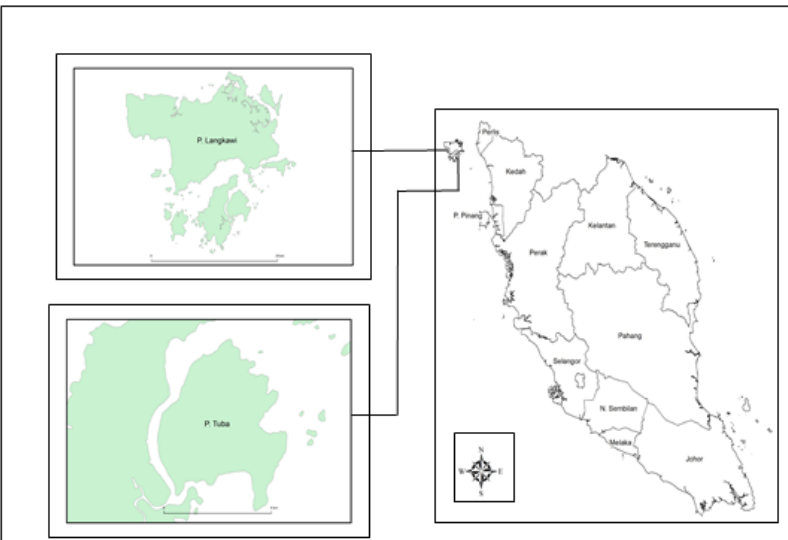

Fig 1: Map of Peninsular Malaysia showing the location of two study sites; Pulau Tuba and Gunung Raya Forest Reserve in Langkawi Archipelago, Malaysia

\subsection{Tree species enumeration}

In each plot, all trees with diameter at breast height (dbh) of $5 \mathrm{~cm}$ and above were tagged and measured its diameter. Collections of specimens were carried out with the help of aborigines (Orang Asli) to climb the trees; or the use of catapult to drop off the leaf samples; and the use of aluminium pruner. Leaves specimens of each measured tree were collected for preparation of voucher specimens and identification. Every specimen collected in the plots were tagged carefully and pressed between newspapers then preserved in alcohol. The specimens were kept in plastic bags and the plastic bags were tied to form an air-tight condition. In the laboratory, the specimens were transferred to dry newspapers. The pressed specimens were then oven-dried at $55^{\circ} \mathrm{C}$ for seven to ten days depending on the type, thickness of the leaf and also the presence of fruits or flowers. The method for pressing the specimens was based on Bridson and Forman [28]. Species identification was made possible up to species level by referring to the keys described in Tree Flora of Malaya [9][10][11][12]

\subsection{Data Analysis}

Data of all tree species were tabulated in Microsoft Excel according to its habitat and were summarized to describe species composition and abundance of the tree communities at each site. Several diversity and richness indices were calculated, amongst them were Shannon Diversity Index, Margalef's Richness Index [13] and Chao- 1 [29]. Comparison of species richness between forests was made using Paleontological Statistics (PAST) Version 2.17 [14] and because of variation in the number of plots among the two forest habitats that reflect unequal sampling effort, thus richness was adjusted by individual-based rarefaction using EcoSim software [15], on the basis of 1000 random iterations. Differences in species diversity between each habitat were visualised via examination of the $95 \%$ confidence intervals for individual-based rarefaction curves. Rarefaction is a probability technique to derive an expectation and variance of species richness for a sample of given size. Floristic patterns were examined by subjecting the sample data to Detrended Correspondence Analysis (DCA), a method derived from reciprocal averaging [16], available in the CANOCO program version 4.0 [17].

\section{Results and discussion}

\subsection{Floristic composition}

Table 2 shows summary of the tree floristic composition at the two study areas in Langkawi Archipelago. Overall, 1062 individual trees were identified comprises of 49 families, 134 genera, and 213 species. Despite lower number of individual trees, GRFR recorded the highest number of family (45), genus (92) and species (135) as compared to PTB with 36 families, 68 genera and 106 species. Vegetation is often dependent on parents' material of the soil. GRFR is granitic and the soils derived from granite and shale is more nutrient-rich and heavily vegetated. In contrast, PTB is underlain by two main rock formations known as Chuping and Setul Formations, granite bodies and alluvium which covers the coastal plain that contributed to fewer plant species grows on the soil. Similar trend was reported at Mule Mountains, Cochise County, Arizona, USA that showed the result of strong associations of tree species with granite substrate [18]. Association of soil characteristics and vegetation patterns have been described in many studies in various forest habitats [19][20][21].

Table 2: Summary of floristic composition of tree communities at two study plots in Langkawi Archipelago

\begin{tabular}{lcc}
\hline & GRFR & PTB \\
\hline Family & 45 & 36 \\
Genus & 92 & 68 \\
Species & 135 & 106 \\
Individual & 478 & 584 \\
\hline
\end{tabular}

\subsection{Species richness}

Table 3 shows the species diversity of tree communities in the two study locations. The trend of Shannon index $(\mathrm{H})$ study can be depicted as GRFR (4.34) > PTB (4.08). The Margalef's species richness index was 16.48 for PTB to 21.72 for GRFR. High evenness is a sign of ecosystem stability, which reflected that no single species dominated the ecosystem and evenness is a subset of measures of equitability. The nonparametric species richness estimator, Chao 1 estimated the number of species based on number of observation (Sobs), which is the total number of species observed in a sample. Chao 1 estimated that 204 species can be expected from GRFR ( $S_{\text {obs }}=135$ species) and 137 species for PTB $\left(S_{o b s}\right.$ $=106$ species). All estimations were higher than the observed values, which is an acceptable estimation for a diverse ecosystem. According to [22], Chao 1 is one of the nonparametric estimators that are the least biased and most precise compared to other estimators (e.g. Chao 2, ACE, ICE, and Jackknife). The Chao richness estimator is based on the concept that rare species infer the most information about the number of missing species. Because the Chao richness estimator gives more weight to the low abundance species, only the singletons and doubletons are used to estimate the number of missing species [29].

Table 3: Summary of floristic composition, diversity and richness indices of tree communities at two study plots in Langkawi Archipelago

\begin{tabular}{|c|c|c|}
\hline & GRFR & PTB \\
\hline No. species $\left(\mathrm{S}_{\mathrm{obs}}\right)$ & 135 & 106 \\
\hline Individual & 478 & 584 \\
\hline Shannon Index $(\mathrm{H})$ & 4.34 & 4.08 \\
\hline Evenness_e^H/S & 0.57 & 0.56 \\
\hline Margalef & 21.72 & 16.48 \\
\hline Chao-1 & 204.4 & 137 \\
\hline
\end{tabular}




\subsection{Floristic variation pattern}

Detrended Correspondence Analysis (DCA) ordination diagram illustrates the dispersion of sampling plots along environmental gradients. The graphic representation of the DCA (Figure 3) clearly grouped the two study areas by geological types. Two study areas were well separated along the DCA axis 1 in terms of species composition, of which the gradient length is 5.037 by the first DCA axis (Table 4). The eigenvalues produced by DCA (axis $1=0.690$, axis $2=0.392$ ) were high, indicating high gradient, i.e. most species occurred throughout the gradients, varying essentially in their abundance [27]. It shows that the strength of speciesenvironment correlations in the first and second axes were high with $69 \%$ and $39 \%$, respectively.

Table 4: Summary tables of DCA analyses of tree species data from two island forests in Langkawi Archipelago

\begin{tabular}{lccccc}
\hline & Axis 1 & Axis 2 & Axis 3 & Axis 4 & $\begin{array}{c}\text { Total } \\
\text { inertia }\end{array}$ \\
\hline $\begin{array}{l}\text { Eigenval- } \\
\text { ues }\end{array}$ & 0.690 & 0.392 & 0.218 & 0.121 & 5.184 \\
$\begin{array}{l}\text { Lengths of } \\
\text { gradient }\end{array}$ & 5.037 & 3.259 & 2.338 & 1.867 & \\
$\begin{array}{l}\text { Cumulative } \\
\text { percentage } \\
\text { variance } \\
\text { of species } \\
\text { data }\end{array}$ & 13.3 & 20.9 & 25.1 & 27.4 & \\
\hline
\end{tabular}

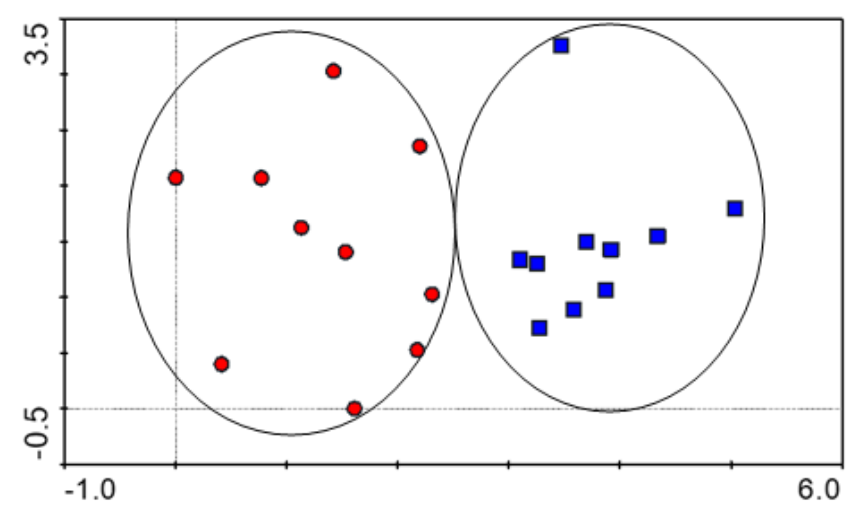

Fig 2: DCA ordination diagram of 20 subplots based on tree species composition data (trees $\geq 5 \mathrm{~cm}$ dbh) in two island forests of Langkawi Archipelago, Malaysia. Shape and colour of symbols represents: red circle $=$ GRFR; blue square $=$ PTB .

Gradient of species change from PTB (granite, limestone and alluvium) to GRFR (granite) sites, implied significant influence of environmental gradient on tree species composition. The DCA ordination illustrates large dispersion of sampling plots from the GRFR site; whilst dispersion of sampling plot of PTB was relatively small and the plots within the PTB were clumped together reflecting the plots are relatively similar floristically.

It is apparent that sampling plots of GRFR are located on the extreme left of DCA axis 1, whilst the plots of PTB are located on the far right of the ordination, reflecting the long environmental gradient showed by the value of gradient length of axis 1 (5.037). The environmental gradient displayed by the ordination reflects different habitat characteristics that influence tree floristic composition of each island forest. Different habitat characteristics of islands in the Langkawi Archipelago are mainly related to different geological and soil characteristics between islands of Langkawi Archipelago, which resulting different types of vegetation on the islands [18].

The granitic habitat features of GRFR and PTB cover approximately $113 \mathrm{~km}^{2}$ of the islands, of which the huge GRFR rises to $878 \mathrm{~m}$, forms the highest part of the island. GRFR is late Cretaceous in age while the smaller pluton of PTB is late Triassic in age.
Petrographically, the granites at both areas are similar and hard to differentiate in the field. It is interesting to note that, PTB granite sill that has intruded the black detrital layer at the base of a hill of Setul Limestone can be seen to the west of the long jetty leading to the village. The granitic intrusion has contorted parts of the dark detrital band into small irregular folds and reacted with the limestone to produce greenish brown skarn deposits of interesting minerals like vesuvianite and grossularite [23][24]. Possibly, differences in geological characteristics of GRFR and PTB contributed to the obvious separation between the plots of the two sites, which indicated dissimilarity in terms of floristic composition.

From the indirect gradient analysis of DCA, it is predicted that there are underlying factors that control the distribution pattern of vegetation communities. Environmental variables are obviously the factors that significantly influence the community patterns. This has been supported by many studies that look at relationships between floristic patterns and environmental gradients, and most of them stated that soil characteristics as one of the significant factors that control the vegetation pattern in a community [25] [26].

\subsection{Rarefaction curve}

In this study, equal sampling size within each habitat could not be established, mainly due to different coverage of each habitat and also due to very steep topography within the habitats. Rarefaction was carried out to enable the richness between these different habitats comparable, because the purpose of rarefaction is to make direct comparison amongst communities on the basis of number of individuals in the smallest sample [15].

After rarefied, the GRFR still had the highest total individual trees (478) representing 45 families, 92 genera and 135 species, while in PTB there were 584 tree individuals representing 36 families, 68 genera and 106 species. These rarefaction curves (Fig 3) clearly indicated that GRFR of granitic habitat was the most diverse as compared to PTB that is granite with layer base of Setul habitat. The slope of the rarefaction curves in all forest types in the present study typically declined as sample size increased, but did not approach an asymptote.

Figure 3 shows the species number of each sampling area at 467 individuals cut-off point that revealed GRFR had the highest estimation of average species number with $137.0 \pm 2.0$ species, followed by PTB $(97.0 \pm 5.0$ species) (Table 5). Overall, the results showed that there were significant differences of species richness between the two sampling areas. The rarefaction curve for the PTB lies significantly below that of the GRFR. Thus, the higher species richness of GRFR was not simply an artifact of the greater number of individuals collected. For example, 350 individuals of 89 species were collected from PTB, whereas a random sample of 350 individuals from the GRFR would be expected to contain approximately 117 species (Figure 3 ).

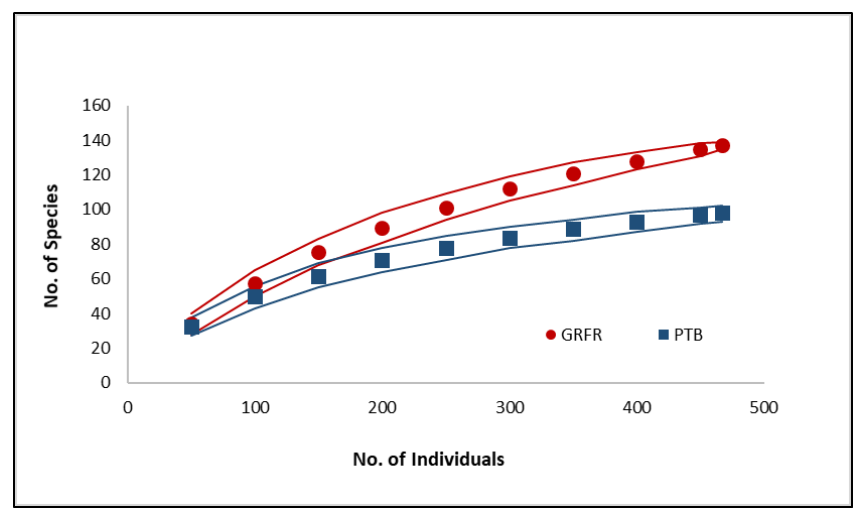

Fig 3: Rarefaction curves at the cut-off point of 467 individuals for each study plot at Langkawi Archipelago, Malaysia. The solid line indicated the 95\% confidence intervals (CI) for each curve. Comparison is considered significant when CI curves did not overlap between each other. 
Table 5: Estimation of average species number for the two island forests in Langkawi Archipelago, Malaysia

\begin{tabular}{ccc}
\hline No. of Individual & GRFR (species) & PTB (species) \\
\hline 467 & $137.0+-2.0$ species & $97.0+-5.0$ species \\
\hline
\end{tabular}

\section{Conclusion}

The results showed that tree communities between two different island forests in Langkawi Archipelago displayed differences in terms of richness and diversity of tree species. The species richness of an island is the outcome of many processes affecting the colonization, evolution, and persistence of island populations. These processes may also vary in their outcome among island groups because of differences in the range of island area and habitat diversity. Floristic variation patterns between the distinct habitats of Langkawi suggested that there are environmental gradients that influenced the floristic patterns. Identifying the key underlying gradients, abiotic conditions and major soil influences on vegetation patterns is essential in formulating plans to protect and conserve island forest habitats of conservation interest.

\section{Acknowledgement}

The authors would like to thank the Forestry Department of Kedah for access permission at the study sites and assistance on the ground. Besides, we would like to thank the School of Environmental and Natural Resource Sciences, Faculty of Science and Technology, Universiti Kebangsaan Malaysia for giving us the permissions of using all the laboratory apparatus and materials. We are also grateful to Ahmad Fitri Zohari for species identification. The acknowledgment continue with financial support from the Universiti Kebangsaan Malaysia through Research University Grant GUP-2013-056 and the Research Management Institute (RMI), Universiti Teknologi MARA (UiTM) under the Excellence Fund (600-IRMI/MyRA 5/3/LESTARI (067/2017).

\section{References}

[1] Balakrishnan NP \& Rao M.K (1983), The dwindling plant species of Andaman and Nicobar Islands, In: An Assessment of Threatened Plants of India (Eds: Jain SK \& Rao RR) Botanical Survey of India, Howrah, pp: 186-210.

[2] Spencer CHB (1996), The reproductive biology and genetics of island plants. Phil. Trans. Bio. Sci., 351: 725-733.

[3] Rasingam L \& Parathasarathy N (2009), Tree species diversity and population structure across major forest formations and disturbance categories in Little Andaman Island, India. Tropical Ecology, 50(1): 89-102.

[4] Mimura N, Nurse L \& McLean RF (2007), Small Islands. Climate change: impacts, adaptation and vulnerability. Contributions of working group II to the fourth assessment report of the IPCC. (Eds.: Parry ML, Canziani OF \& Palutikof JP.) Cambridge University Press, Cambridge, pp. 687-712.

[5] Bramwell D (1979) (ed.) Plants and Islands. Academic Press, London, p.459.

[6] Fa JE, Burn RW, Stanley PMR \& Underwood FM (2004). Identifying important endemic areas using ecoregions: birds and mammals in the Indo-Pacific. Oryx., 38: 91-101.

[7] Vitousek PM (2004), Nutrient cycling and limitation: Hawaii as a model system. Princeton University Press, Princeton; p. 232.

[8] Jahal KCA, Faizul HNN, Kamaruzzaman BY, Shahbudin S, Alam MZ \& Irwandi J (2009), Studies on physio-chemical characteristics and sediment environment along the coastal waters in Pulau Tuba, Langkawi, Malaysia. Aquat Ecosyst Health Manag., 12: 350-357.

[9] Ng. FSP (1978), Tree Flora of Malaya. A manual for foresters. vol. 3. Kuala Lumpur: Longman Malaysia Sdn. Bhd., p.339.

[10] Ng. FSP (1989), Tree Flora of Malaya. A manual for foresters. vol. 4. Kuala Lumpur: Longman Malaysia Sdn. Bhd., p. 549.

[11] Whitmore TC. (1972), Tree Flora of Malaya. Volume 1. Malayan Forest Records No. 26. Longman Malaysia Sdn. Bhd., Kuala Lumpur, p. 471.
[12] Whitmore TC (1973) Tree Flora of Malaya. Volume 2. Malayan Forest Records No. 26. Longman Malaysia Sdn. Bhd., Kuala Lumpur, p. 444.

[13] Magurran AE \& McGill BJ (2011). Biological diversity: frontiers in measurement and assessment. Oxford, Oxford University Press, p. 368.

[14] Hammer $\varnothing$, Haeper DAT \& Ryan PD (2001), PAST: Paleontological statistics software package for education and data analysis, Palaeontologia Electronica, vol. 4, pp. 9pp. http://palaeoelectronica.org/2001_1/past/issue1_01.htm

[15] Gotelli NJ \& Entsminger GL (2005), EcoSim: Null models software for ecology. Version 5.0. Acquired Intelligence Inc. \& KeseyBear, http://homepages.together.net/ gentsmin/ ecosim.htm.

[16] Hill MO \& Gauch HG (1980), Gauch. Detrended correspondence analysis, an improved ordination technique. Vegetatio, 42: 47-58.

[17] Ter Braak CJF \& Šmilauer P (1998), CANOCO Reference Manual and User's Guide to Canoco for Windows: 10 Software for Canonical Community Ordination (version 4). Ithaca, NY: Microcomputer Power p.352.

[18] Thomas RW (1981), Vegetations on limestone and granite in the Mule Mountains, Arizona. Ecology, 62: 469-482.

[19] Khairil M, Wan Juliana WA \& Nizam MS (2014), Edaphic influences on tree species composition and community structure in a tropical watershed forest in Peninsular Malaysia. Journal of Tropical Forest Science, 26(2): 284-294.

[20] Nizam MS, Jeffri AR \& Latiff A (2013), Structure of tree communities and their association with soil properties in two fan-palm dominated forests of east coast Peninsular Malaysia. Trop. Ecol., 54(2): 213-226.

[21] Nurfazliza K, Nizam MS \& Nur Supardi MN (2012), Association of liana communities with their soil properties in a lowland forest of Negeri Sembilan, Peninsular Malaysia. Sains Malaysiana, 41(6) 679-690.

[22] Nizam MS, Rohani S \& Wan Juliana WA (2012), Floristic variation of tree communities in two distinct habitats within a forest park in Pahang, Peninsular Malaysia, Sains Malaysiana, 41(1): 1-10.

[23] Jones CR (1981), Geology and mineral resources of Perlis, North Kedah and the Langkawi Islands. Geological Survey Malaysia District Memoir 17, p. 275.

[24] Sarman M., Komoo I \& Md Desa K (1997), Status Permuliharaan Sumber Geologi Di Malaysia. In: Warisan Geologi Malaysia (Eds.: Komoo I, Leman MS, Md Desa K \& Abdullah I). LESTARI UKM, pp.13-46.

[25] Leman MS (2010), Geoheritage Conservation in Langkawi Geopark Malaysia. Akademika, 80: 19-30.

[26] Tuomisto H, Ruokolainen K, Aguilar M \& Sarmiento A (2003), Floristic patterns along a 43-km long transect in an Amazonian rain forest. J. Ecol., 91: 743-756.

[27] Ter Braak CJF (1995), Ordination. In: Data analysis in community and landscape ecology (Eds.: Jongman RH, ter Braak CJF \& van Tongeren OFR.). Netherlands, Pudoc Wageningen. pp. 91-173.

[28] Bridson D \& Forman L. (1992), The Herbarium Handbook. Revised Edition .Kew: Royal Botanic Garden

[29] Chao A (1984) Non-parametric estimation of the number of classes in a population. Scand. J. Stat. 11: 265-270 